Meta

Journal des traducteurs

Translators' Journal

\title{
Consideration in Translating English/Chinese Contracts
}

\section{Deborah Cao}

Volume 42, numéro 4, décembre 1997

URI : https://id.erudit.org/iderudit/002199ar

DOI : https://doi.org/10.7202/002199ar

Aller au sommaire du numéro

Éditeur(s)

Les Presses de l'Université de Montréal

ISSN

0026-0452 (imprimé)

1492-1421 (numérique)

Découvrir la revue

Citer cet article

Cao, D. (1997). Consideration in Translating English/Chinese Contracts. Meta, 42(4), 661-669. https://doi.org/10.7202/002199ar

\section{Résumé de l'article}

S'appuyant sur des exemples pris dans des textes traduits, l'auteur discute des difficultés que pose la traduction des contrats de l'anglais vers le chinois. On aborde, entre autres, les éléments suivants : les concepts du droit, la langue juridique, les barrières culturelles. L'auteur souligne la nécessité pour le traducteur d'avoir des compétences linguistiques, culturelles et juridiques afin de pouvoir traduire correctement des contrats de l'anglais vers le chinois.
Ce document est protégé par la loi sur le droit d'auteur. L'utilisation des services d’Érudit (y compris la reproduction) est assujettie à sa politique d'utilisation que vous pouvez consulter en ligne.

https://apropos.erudit.org/fr/usagers/politique-dutilisation/ 


\title{
CONSIDERATION IN TRANSLATING ENGLISH/CHINESE CONTRACTS
}

\author{
DEBORAH CAO \\ Griffith University, Nathan, Australia
}

\begin{abstract}
Résumé
$S$ 'appuyant sur des exemples pris dans des textes traduits, l'auteur discute des difficultés que pose la traduction des contrats de l'anglais vers le chinois. On aborde, entre autres, les éléments suivants: les concepts du droit, la langue juridique, les barrières culturelles. L'auteur souligne la nécessité pour le traducteur d'avoir des compétences linguistiques, culturelles et juridiques afin de pouvoir traduire correctement des contrats de l'anglais vers le chinois.
\end{abstract}

\begin{abstract}
This paper addresses some of issues that have arisen in the English/Chinese translation of contracts. As Chinese and English are distinct in their linguistic, cultural and legal traditions, the problems confronting the legal translators are diverse and complex and they sometimes go beyond linguistic or translation boundaries. The paper discusses the areas of translation of legal concepts, legal language and cultural barriers with examples taken from actual practice. It argues that a sophisticated level of linguistic, cultural and legal knowledge is a prerequisite for an English / Chinese contract translator.
\end{abstract}

\section{INTRODUCTION}

Language and law are intricately linked. As Schauer (1993: xi) stated, "law is both a product of and dependent on language." It can also be said that in today's world law is sometimes a product of and dependent on languages in the case of cross-cultural and interlingual communication as the demands for translation of legal texts increase around the world. Legal translation presents challenges to translators, linguists and those working in the new area of studies of jurilinguistics. It is true that translating legal texts from one legal system into the language of a different legal system is difficult, even if the legal languages are closely related, but problems increase considerably when translation is undertaken between very different legal systems which use languages that are not or hardly related (de Groot 1987: 5). Translation of legal texts between Chinese and English is a good example for the latter case. The special translation difficulties in English/Chinese legal documents are absent from other language pairs and are distinct from English/Chinese translation of other text types. There are certain issues that English/Chinese legal translators are obliged to contemplate, some of which will be addressed in this paper.

\section{SOURCES OF PROBLEMS}

As Weisflog (1987: 203) pointed out, the difficulties of legal translation stem from the objective obstacles which are (1) due to the fact that the legal language is a technical language; (2) due to the specific nature of this particular technical language, and (3) due to the fact that the legal language is not a universal technical language, but one tied up with a national legal system. Apart from these obstacles encountered in legal translation in other languages, the special demands associated with translating legal texts between

Meta, XLUI, 4, 1997 
English and Chinese originate from the unique linguistic, cultural, historical and legal traditions that distinguish the Chinese and the English speaking world.

\section{Different Legal Traditions}

One of the major problems in legal translation is caused by the different legal systems of various countries. It is sometimes termed the "system gap" (Weisflog 1987) between one national legal system and another. This gap is particularly evident when comparing and translating English/Chinese legal texts.

The Chinese legal system evolved differently from the major legal systems in the West. Chinese society, from ancient times, has predominantly been a society based on "rule by the elite" rather than "rule of law" (Chang 1994: 4). Well-known representatives advocating this thought included Confucius and Mencius among other ancient Chinese philosophers and thinkers (Chang 1994: 4). This stream of thought has dominated the Chinese social, political and legal systems. In addition, the Chinese society has relied more upon alternative means to solve disputes than resorting to legal recourse. In the past four decades or so, the People's Republic of China's (PRC) legal system has also been evolving around political ideology and it has developed what China terms the socialist legal system. This stands in contrast to the legal traditions in the West such as the English common law system.

One of the practical implications of this is that the Chinese legal system is both unique and fragmentary in the sense that there are peculiar characteristics of the Chinese legal tradition and at the same time many legal concepts and practices that are standard in English common law do not exist or are not explicit in Chinese law. There is a constant absence of legal terminologies that are found in common law but are not reflected in Chinese law or Chinese legal language. Another factor is that many people who are involved in contract formation are not legally qualified and this includes Chinese negotiators and Chinese translators. At present, contract translation accounts for a considerable proportion of legal translation between Chinese and English. These two points have been confirmed by the translator and lawyer informants from the PRC and Australia interviewed for the present study. In terms of translation, this brings to focus the importance of translation and the high level of competence of the legal translators required.

\section{Legal Language as a Technical Language}

From a linguistic perspective, Chinese and English can be at best described as remotely related language and cultural systems. Translation of general non-specialist texts between Chincse and English has problems of its own that derive from the linguistic and extra-linguistic peculiarities of the two languages and cultures. These problems do not disappear in legal translation and the additional problems associated with legal texts accentuate the complications.

Legal language is a technical language and it is a special register in language use. According to Weisflog $(1987: 304)$, when translating legal texts, a transfer takes place not only from one language into another, but from one technical language into another technical language and translation problems also arise where translation is from a more developed into a less developed technical language. In the case of Chinese and English legal language, English is more sophisticated in terms of legal terminology and legal systems whereas Chinese is a less developed technical language of law. This results in the frequent nonexistence of corresponding or equivalent legal terminologies in Chinese.

As distinct from other technical language, legal language is also very much systembound, i.e. tied up with a national legal system (Weisflog 1987: 305). As a result, the translator has to take into consideration the national idiosyncrasies of legal language and 
the national differences as far as the content and the meaning of the legal concepts are concerned, since even when concepts are "formally equivalent", they are not necessarily "materially equivalent" (Weisflog 1987: 305). Here it is the semantic gap, the lack of semantic equivalence, that creates problems when translating from English into Chinese.

\section{Two Identical Contract Versions}

In the context of translating contracts, there is a special phenomenon in China. This is related to the practice of the languages in which business contracts are written.

In the past few years, China has been making considerable efforts to develop and improve its legal system. A large number of laws and regulations, especially in the economic areas have been passed and a multitude of contracts have been signed between Chinese and foreign businesses. According to Article 9 of the Joint Venture Regulations of the PRC promulgated in 1983, contracts may be written in Chinese concurrently in a foreign language agreed to by the parties to the business venture and the Chinese- and foreignlanguage versions shall have equal effect (Cohen 1988: 18). However, as Cohen (1988: 18) pointed out, the Regulation goes on to undermine the significance of the above principle by stating that:

Should there be any non-conformity between the above-mentioned two texts, the Chinese text shall govern.

\section{As Cohen (1988: 18) further stated,}

Despite the lack of legislative support for this provision, Chinese negotiators have been pressing hard for its acceptance, often claiming that it is legally required.

This poses the question of creating substantially identical Chinese and English or other foreign language contracts. These can be contracts translated from the original Chinese or from the original English depending on which sides draft the contracts. In these cases, the translated version assumes a particularly significant role in the business process. Accurate and professional rendering of contracts into Chinese or English is of critical importance, as in the case of a dispute, and if the Chinese contract version were to prevail over the English one, what was written in Chinese should be communicated completely and accurately in English, especially if the litigation were to be handled by a Chinese court and the contract governed by Chinese law.

\section{AREAS OF TRANSLATION PROBLEMS}

Owing to the reasons discussed above, English/Chinese translators assume pivotal roles in contract translation and must be meticulous in dealing with every problem that may arise. Some of the problems that have been encountered in English/Chinese contract translation will now be examined.

\section{Legal Conceptual Problems}

As a result of the separate legal traditions and developmental processes, there are many common law concepts that are either unknown to the Chinese or terms that carry different meanings in Chinese as opposed to English.

According to H. L. A. Hart (1954:41-45), legal language is distinctive because it presupposes the existence of a legal system and presupposes particular rules of law, against the background of which legal language obtains its meaningfulness and particular meaning, and because of the distinctive features of rules of law as rules. This presupposition is one of the distinctive characteristics of legal language. The second distinctive feature, 
argues Hart, concerns the use of legal terms whose uses presuppose the related rules of law that give the words contextual meaning. This means that legal terms have meaning only in the context of the existence of a legal system and only through particular rules of law (Hart 1954 : 41-47; see also Morrison's 1989: 290-297) discussion of Hart). In translation, this may be interpreted as a situation in which legal concepts and terms might not be meaningful at all when translated into another language, the country of which has no corresponding legal system. However, does this imply that legal translators have been attempting to accomplish the impossible and have been engaged in futile exercises, creating illusions?

The translation of the common law concepts of "equity" and "estoppel" into Chinese can be used to illustrate the predicament. Take "equity" for example. Equity is a body of law developed over the centuries by the English Court of Chancery to supply the deficiencies of common law, and administered separately until the fusion of the administration of common law and equity under the Judicature Acts 1873-1875. Equity consists of a miscellany of doctrines and remedies and equitable principles have been incorporated into the common law system. Sometimes in English contracts, there are references to "equitable principles" or "equitable remedies." A different legal concept and practice is being imported when "equity" is translated into Chinese. China has no equivalence for this term either linguistically or in its legal system. To solve the problem, a term was coined in Chinese for "equity" or "law of equity", hengping $\mathrm{fa}^{1}$ (heng literally means "weighing" or "measuring", ping means "fair" or "equal" and $f a$ is for "law"). Here the lexical item was created, but it cannot be considered as a semantic equivalence to the English term. Even if it is followed by a long explanation, it does not have any material or practical meaning as hengping $f a$ is not reflected or recognised in the Chinese law.

Other terms related to equity include "equitable rights" and "equitable interest." They can be translated into Chinese literally as hengping quanli and hengping liyi, but they do not really have any substantive meaning in terms of the Chinese law or in terms of understanding by the Chinese end users of the translated legal texts. If a contract which contains these references is to be governed by Chinese law, in the event of a dispute, no substantive or functional meaning can be interpreted or acted upon regarding these references. This, of course, goes far beyond the problems of linguistics and translation, and thus, is beyond the scope of the present paper.

On the other hand, another term force majeure has a different story. The "force majeure clause" is a common contractual clause in English excluding liability where a party's failure to perform is caused by forces, either natural or human, beyond its control. The problem here is slightly different from "equity". The term force majeure did not originally have a ready version in Chinese. It has since been translated as buke kangli (literally "irresistible force") and now it is often included in Chinese contracts. In fact, the definition of force majeure as described in Article 24 of the Foreign Economic Law of the People's Republic of China (1985) basically corresponds with force majeure as it is understood in common $\mathrm{law}^{2}$. In this case, there is not much difficulty in explaining the concept itself and the contextual meaning can be found in Chinese. It has gained general acceptance in Chinese legal language with an increasing number of people in China recognising its meaning even though the Chinese phrase sounds foreign and awkward. This is one of cases where a corresponding term did not exist in the target language, but a translated term was introduced and a semantic equivalent was found for that concept.

In this regard, Cohen (1988: 19) also discussed difficulties in finding equivalent terms of the Chinese and English versions in contracts. He cited examples of the mistranslation of "mediation" into the Chinese zhongcai which in fact is for "arbitration" and the correspondence between Chinese zhejiu and its English counterpart of "depreciation". 
Cohen argued for the necessity to ensure that the corresponding English and Chinese terms are understood in the same detailed way. Cohen $(1988: 19)$ stated,

Once the equivalent symbols have been selected, even more daunting is the task of making certain that they indeed have congruent definitions in their respective systems and, if they do not, of making the necessary linguistic adjustments and substantive additions to the text to take account of the differences.

Torbert ( $1987: 338$ ) pointed to the substantial discrepancies of legal concepts between the Chinese and English versions also. He attributed the reasons for the inaccuracies of some translated terms to the unfamiliarity of the translators and the Chinese negotiators with legal concepts used in international transactions and to the lack of standardised translation for some of the terms in Chinese (Torbert 1987: 337). Torbert (1987:337-338) cited examples of "disclaimer of a warranty" of merchantability and the "per diem payment" made to a licenser for the value of technical services. He suggested that to avoid disputes regarding obligations in a contract, foreign parties should verify the Chinese text of the contract, if necessary during the negotiations.

Accordingly, one of the dilemmas facing English/Chinese legal translators is to decide whether to translate the legal language or to translate the legal system. As Rayar (1988: 452) advocated, the task of the translator is to translate into another language, not translate into a different legal system, while remaining true to the source language and approximating it as closely as possible with the translation. This is an over-simplified yet workable suggestion. In any event, legal translators are obliged to reflect on some of the more complex problems associated with law and to make the appropriate choice.

The problem of translating alien legal concepts is not new and efforts have made to find possible solutions. As Lane (1982:224) reported, the Internationales Institue für Rechts- und Verwaltungssprache (the International Institute of Legal and Administrative Terminology) attempted to tackle the problem arising from the translation of legal concepts that are unknown in the target language or that do not exist in exactly the same form as in that language. The Institute developed a method for coping with this difficulty. According to the Institute (as reported by Lane 1982), a terminological comparison between one language and the other is based on concepts and terms (Ferdinand de Saussure). A concept is a unit of thought which combines within itself the properties and relationships of things (i.e. material and immaterial objects, situations and circumstances, events actions, procedures, etc.). The properties and the relationships are called the characteristics of the concept. In the sphere of language, a concept is identified by a term which may consist of a single word or of a group of words or even identified by a term which may consist of a single word or of a group of words or even of letters or graphical symbols. When it is necessary to translate a term from one language into a term in another language, it is the task of comparative terminology to go back to the concepts associated with the terms in question and examine whether they do actually correspond (Lane 1982: 224). The Institute compiled and published volumes of the Europaglossar der Rechts-und Verwaltungssprache (European Glossary of Legal and Administrative Terminology) with detailed description and comparison of various legal and administrative terminology in different languages (Lane 1982: 224). It might be advisable in the future to undertake similar work for Chinese and English legal terms by appropriate bodies. This is particularly important considering the fact that differences also exist within the Chinese language system itself and within the Chinese legal language as it is used in China, Hong Kong and Taiwan.

\section{Law has its own Language}

In his comprehensive study of legal language, The Language of the Law, Mellinkoff (1963) summarised the nine distinctive characteristics of legal English. These include the 
frequent use of common words with uncommon meanings; the frequent use of Old and Middle English words, of Latin and old French words; the use of terms of arts and use of argot; the frequent use of formal words; the deliberate use of words with flexible meanings and attempts at times at extreme precision. These language features are among some of the reasons causing problems when translating into Chinese. Here are some examples found in contracts.

Firstly, there are words commonly used in ordinary English that may have different uncommon meanings when used in contracts. The most common word is the use of "shall". In legal English, "shall" is a legal performative and carries the sense of compulsory obligation, meaning "must" as required by the rule of law as opposed to the common usage of "shall" in the sense of "will", "going to" "making suggestions" or "asking for advice" in everyday English. Consequently, when a contract is being translated from English into Chinese, "shall" must be translated into bixu. If it is wrongly translated into jiang or yao ("will"), it will lose the mandatory sense as required by the rule of law and this might have serious legal consequences. Therefore, in the legal context, a simple word such as "shall" may have a substantially different meaning and a contract containing such a word may impose a different contractual obligation if translated differently. This problem might appear if translators are unfamiliar with legal language and are not aware of the legal consequences that might arise if jiang is to be used instead of bixu.

There are numerous other examples of simple terms which may have general meanings as used in the everyday sense, but also have significantly different meanings in a particular context of law. One such term is "consideration" as used in contract law. "Consideration", which is a very important concept in contract law, but does not have the same significance in the Chinese legal system, needs to be carefully translated into Chinese. In everyday English, "consideration" means "continuous and careful thought". In contract law, "consideration" is employed differently from its ordinary usage to refer to "the price paid for a promise". A promise contained in a simple contract cannot be enforced unless it is given for consideration. Under the common law system, when a contract is signed, each party has to provide consideration in order to create a binding legal relationship. When translating this into Chinese, the translator needs to distinguish the legal sense of "consideration" from its ordinary meaning and to render it into yueyin, youchang fuwu or duijia as used technically. These Chinese terms are completely unrelated to the ordinary Chinese word for the regular word for "consideration" (kaolu). Hence, the title of the present paper "Consideration in Translating English/Chinese Contracts" is not entirely translatable in the sense that it is impossible in Chinese to retain the double meanings of "consideration" as it carries in ordinary and legal English. Only the meaning of "careful thought" can be transfered into Chinese. We can see that translators are required to be extremely cautious in accurately comprehending the original English meaning so as to choose the right Chinese equivalent. This demonstrates the necessity of an adequate knowledge of legal English and Chinese and a basic knowledge of the two legal framework.

Apart from words with multiple meanings or words whose meanings vary in legal contexts as opposed to general English usage and which might turn out to be faux amis for translators with insufficient knowledge of legal language, another category of problems associated with legal language is the attempts at precision in legal English. Problems occur with the terms of "mortgage" (diya), "charge" (diya), "pledge" (diya), "lien" (diya quan), "hypothecation" (diya), "security interest" (diya, diya pin). For the English terms, each carries its own connotations, but Chinese did not distinguish these terms as does English and there were no separate Chinese words for these different English terms. Usually these terms had to be covered by the one term diya (mortgage) in Chinese. The situation has improved to some extent since the drafting of this paper. Laws 
and regulations related to mortgage have been promulgated in the PRC in the past year or so. Some of the English legal terms and concepts have been adopted in Chinese law with China's own statutory definitions.

The above examples are to illustrate a number of the types of problems Chinese/ English legal translators are often confronted with. They also support the argument that a detailed knowledge of the two linguistic, cultural and legal systems is critical for the successful rendition of legal texts, and in this case, of contracts.

\section{Cultural Barriers}

English/Chinese legal translation also has problems associated with cultural differences. These sociolinguistic problems are reflected in the types of clauses used in the original Chinese contracts.

English common law culture stresses relevance. Parties to a contract should only commit themselves to what is relevant to the business transaction and what can actually be achieved by the parties. The incorporation of general principles and high ideals are often avoided for fear that it might increase ambiguity. On the other hand, the Chinese often regard contracts as statements of good intention and believe that the parties to a contract can work out the details and solve any problems as needs arise. Accordingly, statements of general principles are often part and parcel of business contracts. For example, clauses such as the following can be often found in Chinese contracts:

Wei jinyibu jiakuai jingli zhenxing bufa, cujin jia yi shuangfang de gongtong fazhan, benzhe pingdeng huli, huxiang hezuo, huxiang zhichi de yuanze, jing shuangfang chongfen xieshang, dacheng xieyi ruxia.

(In order to further accelerate the efforts for economic revitalisation, to promote the joint development of Party A and Party B to the contract, and in accordance with the principle of equality and mutual benefit and the principle of mutual cooperation and support, the present agreement has been reached between the two parties after extensive consultation.)

The linguistic phenomenon is partly a reflection of how Chinese think and how they traditionally view contracts. The Chinese regard the contracts as a part of the process of establishing and maintaining a long-term friendly relationship between the parties. Thus, words such as "long-term friendship", or "equality and mutual benefits" are often interspersed in Chinese contracts. The Chinese parties regard them as very important. However, for some of the vague and general terms used in the Chinese contracts, if translated into English, they may entail the risk of making the English contracts void for uncertainty under common law. This highlights the discrepancy between the Chinese and English positivist legal culture and the consequent language used.

Another example,

Yifang [...] yuanzeshang baozheng fuqing meikuan.

(Party B, in principle, guarantees to make payment for the purchase of coal in...)

Here yuanzeshang (in principle) can cause some ambiguity and uncertainty. Party B might choose not to pay under circumstances not covered by the "in principle". Deliberate ambiguity and imprecision is sometimes a feature of the Chinese language and a feature of Chinese business practice, often leaving things open to interpretation. It also gives flexibility to change when the Chinese find it necessary in their favour. This stands in contrast to the clauses in English contracts. If a dispute arises, every word and provision in an English contract should assist with the interpretation of the contract. In Chinese contracts, some clauses and phrases do not have any substantive significance. This highlights the discrepancy between the Chinese legal practice and the English positivist legal culture and the language used in English contracts. 
The above examples are related to the cultural differences between the Chinese and English people. They are, again, associated with the legal language and contract drafting of the Chinese and English legal and business communities. For English/Chinese contract translators, the overriding responsibility is to translate the original clauses faithfully, accurately and in their entirety. At the same time, they should be alert to the types of problems as discussed above so that parties to a contract might become aware of some of the linguistic and extralinguistic barriers separating them and appreciate the dilemmas facing the translators. It will be up to the parties to a contract, not the translators, to determine what is to be included in a contract. There is a long and slow process in bringing together both the legal professionals and legal translators involved in contract drafting and negotiation from the Chinese and English speaking countries in making Chinese/ English contracts admissible both linguistically and legally.

\section{CONCLUSION}

The above discussion demonstrates that the study of Chinese/English contract translation is of practical and theoretical significance from linguistic and legal perspectives. To be able to effectively translate legal texts between Chinese and English, an advanced level of proficiency in English and Chinese in terms of general and legal language is a prerequisite for any contract and legal translators. This must also be combined with an intimate degree of familiarity with the two cultural and legal systems and with sophisticated translation strategies in dealing with various complex situations. At present, such an ideal situation is still a long way from reality.

\section{Acknowledgment}

The author wishes to express her gratitude to Mr Don Boyd of Deacons Graham \& James Lawyers and the legal and translation staff in its Beijing office, PRC, for their kind assistance to her during her doctoral study in the area of legal translation, of which the present paper is a part. A word of thanks also goes to Mr Andrew Godwin and Mr James Zeng, lawyers from Minter Ellison of Melbourne, Australia, who provided invaluable input in the discussion of English/Chinese translation of contracts which formed part of the present paper. Any error in interpretation rests with the author.

\section{Notes}

1. The Pinyin system of Romanisation of the Chinese language is used for all the Chinese texts.

2. Article 24 of the Foreign Economic Law of PRC adopted on March 12, 1985 states:

An event of force majeure means an event that the parties could not foresee at the time of conclusion of the contract and the occurrence and effects of which cannot be avoided and cannot be overcome. (Cohen $1988: 168)$

\section{REFERENCES}

CHANG, Hsin (1994): Zhongguo falu: jieshuo yu shiwu (The Chinese Legal System Explained), Hong Kong, the Chinese University of Hong Kong.

COHEN, Jerome A. (1988): "Negotiating Business Contracts with China", J. A. Cohen (Ed.), Contract Laws of the People's Republic of China, Hong Kong, Longman, pp. 13-26.

DE GROUT, G. R. (1987): "Problems of Legal Translation From the Point of View of a Comparative Lawyer", P.H.M. Gerver, E.H. Hondius \& G.J.W. Steenhoff (Eds.), Netherlands Reports to the Twelfth International Congress of Comparative Law, The Hague, T.M.C. Asser Instituut, pp. 1-19.

HART, H. L. A. (1954): "Definition and Theory in Jurisprudence", The Law Quarterly Review, 70, pp. 37-60.

LANE, Alexander (1982): "Legal and Administrative Terminology in Translation Problems", J.-C. Gémar (Ed.), Langage du droit et traduction, Montreal, Linguatech / Conseil de la langue française, pp. 219-231.

MELLINKOFF, David (1963): The Language of the Law, Boston, Little, Brown and Company.

MORRISON, Mary Jane (1989): "Excursions Into the Nature of Legal Language", Cleveland State Law Review, 37, pp. 271-336. 
RAYAR, W. (1988): "Problems of Legal Translation From the Point of View of a Translator", P. Nekeman (Ed.), XIth World Congress of FIT Proceedings: Translation, Our Future, Maastricht, Euroterm, pp. 451-454.

SCHAUER, Fredrick (Ed.) (1993): "Introduction", Law and Language, Dartmouth, Aldershot, pp. XI-XVI.

TORBERT, Perston M. (1987): "Contract Law in the People's Republic of China", M.J. Moser (Ed.), Foreign Trade, Investment, and the Law in the People's Republic of China, New York, Oxford University Press, pp. 321-342.

WEISFLOG, W. E. (1987): "Problems of Legal Translation", Swiss Reports presented at the XIIth International Congress of Corporative Law, Zürich, Schutthess, pp. 179-218. 